НАГИБИНА Ирина Геннадьевна,

канд. филол. наук, доцент кафедры восточных языков Института филологии и языковой коммуникации Сибирского федерального университета (г. Красноярск).

Электронная почта: irina_nagibina@mail.ru.

САВКИН Дмитрий Александрович,

канд. полит. наук, директор Байкальского института БРИКС, проректор по международной деятельности Иркутского национально-исследовательского технического университета (г. Иркутск).

Электронная почта: d.savkin@istu.edu

\title{
Компоненты китайского банковского дискурса
}

\section{УДК 811.581'42:330.446.23 DOI https://doi.org/10.24866/2542-1611/2021-3/96-107}

институииональная коммуникаиия,

китайский банковский дискурс,

участники,

хронотоп,

стратегия коопераиии, иенности,

прецеедентные тексты, дискурсивные формульь
Предлагаемая статья посвящена описанию копонентов китайского банковского дискурса и их языковой реализации в дискурсе работников китайской банковской сферы. В рамках исследования рассмотрена вербализация интерактивного институционального общения, обусловленного заданными рамками статусно-ролевых отношений «банк-клиент» и факторами, среди которых участники общения, хронотоп, концепты и ценности, цели и стратегии. Актуальность работы обусловлена недостаточной изученностью китайского институционального дискурса в целом, и китайского банковского дискурса как его типа, в частности. Проанализированные компоненты китайского дискурса формируют специализированную разновидность общения внутри банковской сферы КНР, которая регулируется в соответствии с нормами изучаемого социума.

Банковский дискурс является одной из разновидностей институционального дискурса, представляющую собой многомерное коммуникативное образование, состоящее из множества элементов, пересекающихся и взаимодействующих друг с другом. Банковский дискурс также является неотъемлемой частью современного социума. Он осуществляется в рамках банковского пространства между клиентами и агентами банков, включая в себя лингвистические и экстралингвистические средства.

Н.Г. Бурмакина и Л.В. Куликова в своей работе «Академический дискурс: институциональность, стиль, жанры» выделили характеристики академического дискурса. Данные характеристики можно использовать применительно к банковскому дискурсу, т.к. академический и банковский дискурс являются типами институционального дискурса и могут обладать схожими чертами. Таким образом, рассматривая банковский дискурс как тип институционального дискурса, можно выделить следующие характеристики институциональности:

- банковское общение регламентировано комплексом норм, правил, ограничений;

- банковской коммуникации присущи шаблонность, клишированность;

- субъекты банковской коммуникации не действуют спонтанно, они исполняют установленные социальные роли; 
- субъекты банковского общения могут обладать как равными статусами, так и находиться разных статусных отношениях [1].

Специалист в сфере профессиональной коммуникации Т.Ю. Махортова рассматривает банковский дискурс как вербализацию интерактивного институционального общения, обусловленного заданными рамками статусно-ролевых отношений банк-клиент и факторами, среди которых участники общения, хронотоп, концепты и ценности, цели и стратегии, прецедентные тексты и так далее. Также банковский дискурс можно определить как особую специализированную разновидность институционального общения [6].

Т.Ю. Махортова подчеркивает следующие признаки банковского дискурса, необходимые для его исследования:

- конститутивные признаки, включающие участников, условия, организацию, способы общения;

- признаки институциональности, конкретизирующие конститутивные признаки дискурса в виде типичных хронотопов, символических и ритуальных действий, речевых клише;

- признаки типа институционального дискурса, характеризующие тип общественного института на базе анализа его ключевых концептов;

- нейтральные признаки, включающие общедискурсивные характеристики, типичные для любого типа общения, личностно-ориентированные признаки и признаки, транспонированные из другого дискурса [6].

В своей статье «Информационно коммуникативная среда банковского дискурса» А.В. Федорова (Жарова) определяет современный банковский дискурс как «многомерный феномен, который включает лингвистические и экстралингвистические компоненты, а также объединяет основные концепты, зависящие от цели, стратегий, социального пространства дискурса». Несмотря на сложившийся стереотипный образ солидного и труднодоступного института, современный банк стремится создать положительный и доверительный образ в рамках социума, тем самым становясь более понятным и простым для клиентов банковской сферы [8].

Основным инструментом информационно коммуникационной политики банка является:

- личное общение;

- общение по телефону;

- почтовая связь;

- интернет и так далее [8].

Для банковского дискурса характерна шаблонность.

Коммуникация в рамках банковской деятельности осуществляется по клишированной схеме, которая включает определённые этапы. Однако эта типичная для банковского дискурса схема не является постоянной и нерушимой. Банковский дискурс включает в себя различные институциональные формы общения, которые напрямую относятся к банковской деятельности. Он находит реализацию в ситуациях специфической деятельности. Например, консультация в банке, консультация с клиентом по средствам сотовой связи, открытие счёта и другие виды операций.

В современном мире ключевым фактором при определении качества услуг, предоставляемых в той или иной организацией (в том числе в банке), является язык, используемый в процессе предоставления тех или иных услуг. Банк, будучи важнейшим социально-экономическим институтом, строит свою деятельность и влияет на социум 
через дискурс, именно поэтому в банковских организациях уделяется большое внимание речи работников.

Таким образом банковский дискурс является сложным многосторонним образованием, которое состоит из ряда элементов, находящихся в определённых отношениях друг с другом. Банковский дискурс - это специализированное общение между банком и клиентами, которое, как и другие виды институционального дискурса, регулируется в соответствии с нормами определённого социума. Банковский дискурс обладает особыми признаками и характеристиками, в рамках которых мы можем его изучать.

Для подробного анализа банковского дискурса необходимо учитывать и подробно рассматривать все аспекты коммуникации: социальную среду, коммуникантов, лингвистические и экстралингвистические факторы, контекст и многие другие компоненты. В данной работе мы опираемся на компоненты, обозначенные В.И. Карасиком в его работе «О типах дискурса». В след за учёным мы придерживаемся понятия компонентов как уникальных составных элементов, образующих каждый из видов дискурса и определяющих его особенности.

По мнению В.И. Карасика, характеристика институционального дискурса требует рассмотрения следующих компонентов:

1) участники, т.е. их характеристики - возраст, социальный статус, а также другие факторы, влияющие на речевое поведение;

2) хронотоп, т.е. обстановка, характерная для институционального дискурса работников банковской сферы в Китае;

3) цели, т.е. специфические цели общения присущие участникам данного социального института;

4) ценности, т.е. ключевые концепты;

5) стратегии, используемые для достижения целей;

6) прецедентные тексты;

7) дискурсивные формулы, т.е. своеобразные обороты речи, свойственные общению в данном социальном институте, анекдоты [4].

Для подробного и детального анализа такого вида институционального дискурса, как банковский дискурс, рассмотрение данных компонентов является целесообразным, так как все эти факторы обуславливают речевое поведение служащих китайского банка. Банковский дискурс обладает особенностями, которые отличают его от других видов коммуникационной деятельности. Каждый компонент обладает своей уникальностью и особенностями в рамках китайского банковского дискурса, который позволяет отделить китайский банковский дискурс от других видов институционального дискурса.

В рамках данного исследования были проанализированы аудио и видеоматериалы аутентичного китайского банковского дискурса, собранные в банках Китая: «Промышленный и коммерческий банк Китая» («中国工商银行»), «Сельскохозяйственный банк Китая» («中 国农业银行》), «Промышленный банк» (《兴业银行》).

\section{1. Участники китайского банковского дискурса}

Участниками китайского банковского дискурса являются агент и клиент, то есть рабочие китайского банка и клиенты, которые обращаются в банк за определёнными услугами. По нашим наблюдениям, рабочие китайского банка - это мужчины и женщины в возрасте от 30 до 50 лет. Анализу была подвергнута речевая деятельность представи- 
телей таких должностей, как менеджер по работе с клиентами, операционист, охранник, т.е. работники, которые постоянно контактируют с клиентами различных социальных слоёв и возрастов. Возраст клиентов, которые обращаются за определённой услугой в банк может напрямую влиять на языковые единицы, используемые работникам. Несмотря на то, что работники банковской сферы должны относиться к каждому клиенту одинаково, рассматривать их как равных, в обращениях банковских рабочих к представителям старшего возраста гораздо отчётливее видно уважительное отношение. Этот феномен напрямую связан с заложенной в китайской духовной традиции установкой на уважение и почитание старших людей.

Например, по отношению к клиентам более старшего возраста можно услышать следующие обращения: 先生 / «господин», 女士 / «госпожа»,

大娘 / «госпожа» (обычно к пожилым женщинам). Также используется уважительное местоимение 您 / «Вы».

К представителям молодого поколения работники могут использовать такие обращения, как 美女 / «девушка», 小伙子 / «молодой человек». Также возможно такое неформальное обращение, как 大哥 / «вы», которое обычно может применяться по отношению к ровесникам.

Работники китайской банковской сферы крайне редко напрямую спрашивают имена клиентов и обращаются к ним по именам. Сами работники китайской банковской сферы также вербально не эксплицируют собственные имена клиентам, так как каждый работник имеет бейдж, в соответствии с которым клиент может обращаться к агенту.

Таким образом, от различных характеристик участников китайского банковского дискурса, а именно пола, возраста, социального статуса, речевого поведения самих клиентов и так далее, зависит сам ход банковского дискурса и языковые единицы, которые будут использоваться агентами, т.е. работниками китайской банковской сферы.

\section{2. Хронотоп работников китайской банковской сферы}

Хронотопом китайского банковского дискурса является обстановка, типичная для диалога клиента с агентом, а именно территория банка в определённые дни и часы его работы. Совокупность проанализированных диалогов осуществлялась в общем зале отделения банков.

Как правило, банки в Китае работают с 8 до 20 часов. Однако развитие современных технологий позволило банкам Китая обеспечить круглосуточный доступ клиентов к некоторым банковским услугам. Например, снятию и внесению наличных на карту. В связи с этим на территории банковского отделения, внутри или снаружи, работают несколько банкоматов. На корпусе данных банкоматов или непосредственно над ними часто можно встретить такие фразы, как 欢迎光 临 / «Добро пожаловать», 欢迎使用АТМ自动取款机 / «Добро пожаловать к использованию банкомата». Данная фраза выполняет функцию приветствия для каждого клиента, в независимости от того, контактирует ли клиент с персоналом (фото 1).

Также на полу перед терминалами, кассовыми окнами и в остальных местах, где возможно скопление очереди можно увидеть фразу 请 


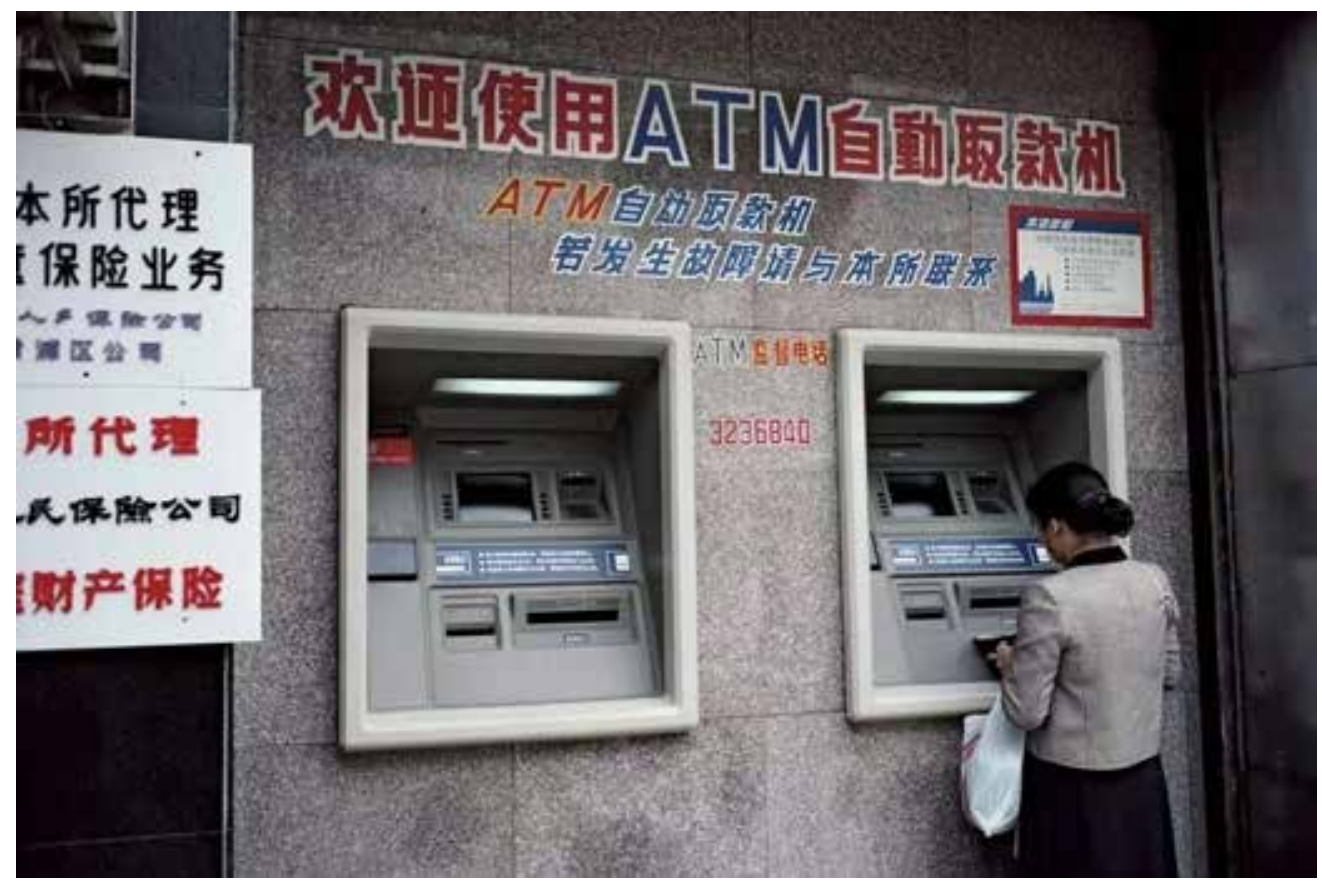

Фото 1. Банкоматы Промышленного и коммерческого банка Китая. Источник: фото авторов.
在一米线外等候 / «Пожалуйста, ожидайте за линией». Так как очереди в китайских банках бывают достаточно большими, данная фраза используется для контроля клиентов и поддержания порядка в помещении банка. Также в помещении китайского банка распространено такое явление, как 安全提示 / «Safety Tips» / «Инструктаж по технике безопасности», в которых указаны основные правила самостоятельного успешного выполнения банковских операций, а также оповещение у круглосуточной помощи и консультации по различным вопросам и проблемам, возникшим у клиентов в ходе выполнения той или иной банковской операции (фото 2).

Таким образом, система китайского банка устроена так, что все условия располагают к успешной и комфортной деятельности клиента на территории банка: 顾客满意是我最大的心愿 / «Удовлетворённость клиента - это наше заветное желание».

В связи с тем, что жители КНР очень часто пользуются услугами банков, вне зависимости от их социального статуса, банки в Китае расположены в различных районах, как в престижных, так и в обычных районах города. Интересен тот факт, что одни и те же банки могут располагаться на небольшом расстоянии друг от друга, так что люди со всех районов имеют постоянный доступ к ним.

В целом хронотоп китайского банковского дискурса - это любая официально-деловая обстановка, в рамках которой осуществляется дискурс, ограниченный по времени установленными рамками рабочего дня агентов. Такая официально-деловая обстановка обеспечивает необходимые условия для осуществления банковского дискурса и 
определяет характерные черты дискурса работников китайских банков.

\section{3. Цели и стратегия кооперации китайского банковского дискурса}

Основной целью работника китайского банка является вовлечение клиента в коммерческую деятельность банка, установление постоянных деловых отношений между банком и клиентом. Второстепенными целями любого работника китайского банка являются получение зарплаты за успешно проделанную работу, а также создание и сохранение благоприятного имиджа организации, участником которой он является, так как интересы общества и организации стоят на первом месте в иерархии ценностей китайской культуры. Стремление к достижению данных целей проявляется в китайском банковском дискурсе с помощью фраз и выражений, демонстрирующих уважение и открытость к клиенту. Чаще всего в речи китайских банковских работников реализуется стратегия

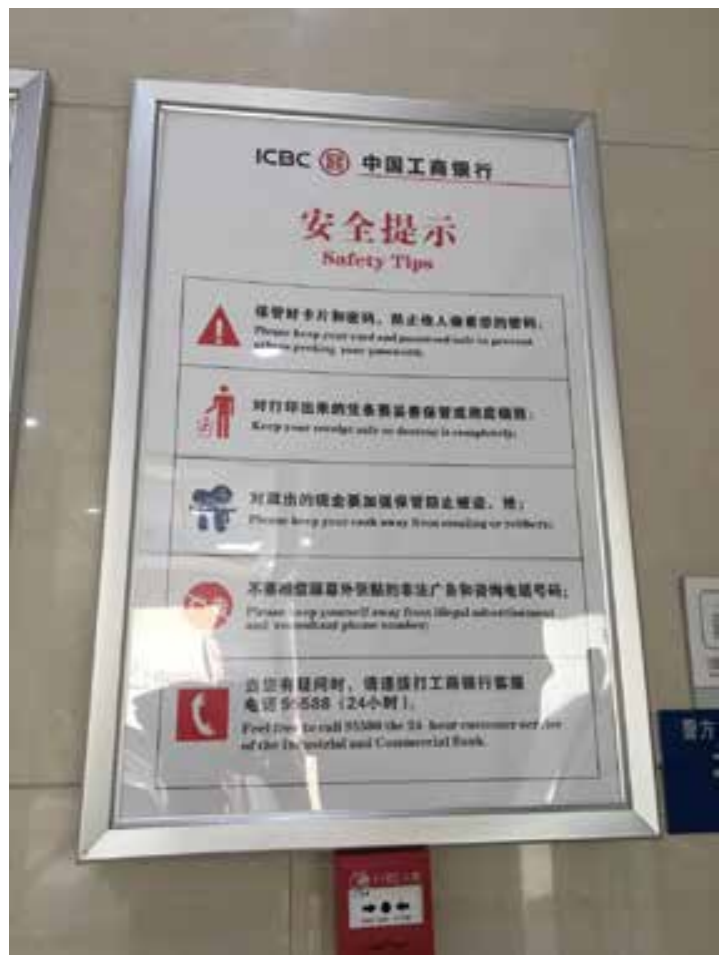

Фото 2. Инструктаж по технике безопасности в Промышленном и коммерческом банке Китая. Источник: фото авторов.

В данных примерах, с помощью общеупотребительной формы обращения 请问 / «разрешите спросить», воплощается стратегия вежливости.

- 您讲慢写好吗? / «Пожалуйста, говорите помедленней».

- 你填写表格下来好吗? / «Пожалуйста, заполните бланк».

В данных примерах мы видим, что для просьб работники китайских банков часто используют вопросительную форму предложения, с добавлением вопросительной частицы好吗 в конце, тем самым смягчая модальность просьбы.

Также работники китайских банков используют утвердительную форму предложения для просьб, рекомендаций и так далее, в начале которых, как правило, используется каузативный глагол 请, который выполняет вежливую побудительную функцию, и в то же время относится к официально-деловому стилю:

- 请到7号柜台办理 / «Пройдите к 7 окошку».

- 请到开放式柜台办理 / «Пройдите к свободному окошку».

- 请填张存款单, 写明数额、姓名、地址和工作单位 / «Заполните депозитную квитанцию, укажите имя, адрес и место работы».

- 请写上你的姓名、证件号码和联系方式 / «Укажите свое имя, номер документа и контакты». 
- 请收好单据 / «Возьмите квитанцию».

- 请出示护照 / «Ваш паспорт».

- 请签名 / «Распишитесь, пожалуйста».

- 请告诉我你要换多少 / «Какую сумму хотите обменять?»

- 请清点一下现金 / «Пересчитайте, пожалуйста, сумму».

- 请输入密码 / «Введите пароль, пожалуйста».

- 请告诉可以为您效劳的 / «Могу я вам чем-то помочь?»

В следующих примерах можно видеть коммуникативные клише, которые используются работниками китайских банков при выражении просьбы ожидания. Их использование также демонстрирует уровень уважения и вежливости по отношению к клиенту:

- 好的, 请稍等 / «Пожалуйста, подождите немного».

- 请等一下/ «Подождите немного».

- 等一会儿/ /Секундочку».

- 请等一等/ «Пожалуйста, подождите».

- 请先在大厅休息一下, 马上会有客户经理来帮助您 / «Присядьте пока в зале, скоро наш менеджер подойдет к вам».

Используя стратегию вежливости, работники китайских банков влияют на сознание клиента, формируют положительные стереотипы клиента по отношению к банку и его устройству, к его деятельности и услугам, устанавливают и поддерживают отношения между банком и клиентами. Таким образом, речевая деятельность работника китайского банка направлена на реализацию как своих личных целей, так и глобальных целей банка.

\section{4. Аксиологический фактор как основной компонент китайского банковского дискурса}

Понятие ценности является одним из основных понятий в рамках коммуникационной деятельности человека. Ценности определяют сущность человека, совокупность ценностей, формирующихся на протяжении всего существования той ли иной культуры, а также являются составляющим человеческого сознания и определяют его деятельность [2]. А.В. Кирьякова в своей работе упоминает, что «всё многообразие предметов человеческой деятельности, общественных отношений и включённых в их круг природных явлений, может выступать в качестве ценностей как объектов ценностного отношения, может оцениваться в плане добра и зла, истины и не истины, красоты и безобразия, допустимого или запретного, справедливого и несправедливого» [5]. Действительно, в каждой культуре ценности определяют свои рамки и грани человеческой деятельности, оценивая человеческое существование во всех сферах жизни, таких как семья, работа и т. д.

Ценности той или иной культуры, в данном случае культуры Китая, дают чёткую характеристику её представителей и имеют свойство сохраняться в языке и отражаться в ходе коммуникативной деятельности. В общем пространстве духовной культуры на всех этапах её эволюции присутствуют ценности и идеалы, которые регламентируют социальное поведение человека [3]. Порядок, гармония, совершенство, иерархия, социальная справедливость, семья, мораль - это главные ценности традиционного китайского общества. Одна из основополагающих ценностей китайского традиционного общества, а именно порядок, является одним из главных факторов, влияющих на 
банковский дискурс. Житель Поднебесной с детства воспитывается с осознанием необходимости соблюдения такого понятия, как 礼 / «ритуал». Само понятие 礼 многогранно, оно может относится и к философским, и к политическим, и к моральным представлениям. В нашем случае понятие 礼 отвечает за соблюдение работниками китайского банка правил поведения и церемоний, присущих данному институту. Концепция 礼 удерживает сотрудника в рамках нормы, позволяя использовать ритуалы и этику для достижения социальной гармонии в рамках такого социального института, как банк. Наряду с понятием ритуала в китайском обществе действуют устойчивые стандарты поведения, речи, обрядов и церемония фиксируемое таким понятием, как 道 / «мораль», которое должно соблюдаться всеми членами общества без исключений. Мораль и ритуал в рамках такого социального института, как банк, говорят о послушании и подчинении рабочих руководству и служению на благо имиджа и целей банковской организации, так как интересы общества должны ставиться превыше собственных интересов.

Интересно, что Китай является страной, где, несмотря на мировое развитие и глобализацию, по сей день сохраняются многовековые устои и традиции, которые в то же время гармонично сочетаются с западными новшествами. Осознавая необходимость развития и принятия новых веяний и изменения образа мышления, Китай попрежнему следует своим духовным традициям, параллельно перенимая западные идеи, реализуя их на свой манер. Молодые люди Китая, которые так же являются представителями банковской сферы в Китае, трудятся изо всех сил ради возвышения престижа страны и сферы своей деятельности. Проведённый в 2015 году опрос С.А. Митькиной показал, что высшие ценности для китайской нации - это по-прежнему общественные ценности [7].

В Китае также существует такое понятие, как 职业道德 / «профессиональная этика». 职业道德 - это базовая этика, которой люди должны руководствоваться в своей профессиональной деятельности. Это общий термин для 职业品德 / «профессиональной морали», 职 业纪律 / «профессиональной дисциплины», 专业胜任能力 / «профессиональной компетентности», 职业责任 / «профессиональной ответственности». Профессиональная этика - это моральная ответственность и обязательства определенной отрасли перед обществом. 职业 道德 не имеет определённой формы, она воплощается в концептах, привычках и убеждениях [9].

Банковское дело - это особая сфера услуг с большим социальным воздействием, поэтому от работников банковской сферы требуют четко следовать профессиональной морали: соблюдать дисциплину, быть честным и надежным, служить людям, вносить свой вклад в общество, эффективно осуществлять свою деятельность, соблюдать банковскую тайну, уважать клиента.

Профессиональная этика работников китайских банков - это моральный кодекс, который соответствует особым требованием банка, совокупность моральных качеств, связанных с профессиональной деятельностью сотрудников банка. Это не только требования к сотрудникам банка, но и моральная ответственность и обязательства банковской сферы перед обществом. Профессиональная этика является основным составляющим общественной морали. Профессиональная 
этика - это то, как каждый работник китайской банковской сферы относиться к своей работе, его жизненная позиция, система ценностей.

Высокий уровень профессиональной этики является гарантией качественного обслуживания клиентов агентами, если же профессиональная этика на низком уровне, сложно предоставить качественные услуги. Не следуя правилам так называемой 职业道德, работник банка не только наносит вред репутации банка, но и теряет своё лицо, что называется 丢面子 / «потерять достоинство» и является недопустимым, так как сохранение репутации, или 保全面子, является необходимым.

Основные правила и нормы банковского персонала отражает речевая формула 客户第一, 信誉至上, 爱岗敬业 / «Клиент всегда прав, репутация превыше всего, люби своё дело».

Одним из главных понятий, относящихся к ценностям работников банка, является 文明礼貌 / «культура и вежливость». Ценностная установка 文明礼貌 - это составляющая имиджа предприятия, так как имидж каждого отдельного сотрудника банка, его поведение оказывают влияние на всё предприятие. Она также требует соблюдения определённых языковых норм от работников банковской сферы в Китае, таких как использование естественного языка, доброжелательного тона, соблюдение умеренного темпа речи, соблюдение лаконичности речи, использование путунхуа, использование уважительной формы обращения, избегание слов-табу, умение проявлять языковую сдержанность при возникновении споров с клиентами, умение улыбаться при общении с клиентами.

Таким образом, ценности, сформированные в Китае на протяжении многих столетий, ярко отражаются в речи работников китайского банка. Национальные ценности традиционной культуры Китая гармонично сочетаются с приобретёнными современными веяниями. Эти ценности работников китайской банковской сферы заключаются в исполнении профессиональной этики, соблюдении иерархии в общении с клиентами и начальством, стремлении следованию профессиональной морали и нормам, что в свою очередь реализуется в речи. Соблюдение ценностей обеспечивает успешное общение между агентом и клиентом.

\section{5. Прецедентные тексты и дискурсивные формулы, используемые работниками китайских банков}

Прецедентные тексты китайского банковского дискурса являются значимыми компонентами для работников банков в Китае, они знакомы любому представителю банковской сферы. Прецедентные тексты играют важную роль в банковской деятельности.

Прецедентные тексты, а именно афоризмы, выражения, используемые банковскими работниками в речи:

- 顾客满意是我最大的心愿 / «Удовлетворённость клиента - это наше заветное желание».

- 服务就是我们的使命 / «Наша служба - это наше призвание».

- 全心全意为顾客服务 / «Служить клиентам всем сердцем и всеми помыслами».

- 客人的满意是我们的事业的动力 / «Удовлетворённость клиента наша мотивация».

- 周到的服务才能赢得顾客的信任 / «Доверие клиента можно заво- 
евать хорошим обслуживанием».

К дискурсивным формулам китайского банковского дискурса можно отнести анекдоты, которые используются работниками китайских банков для сближения с клиентом и установления контакта:

请写证件号码。- 我的吗? - 如果想写我的 / «- Напишите номер документа. - Моего? - Ну, если хотите, напишите моего».

- 你好, 我的卡被你们的取款机吃了。- 不要着急, 我们马上让它 吐出您的卡 / «- Здравствуйте, ваш банкомат «зажевал» мою карточку. - Не волнуйтесь, сейчас мы заставим его «выплюнуть» вашу карточку».

- 你好, 我是来提钱的。 - 别和我提钱, 提前伤感情, 大哥, 你最 好到提款机面前提, 他没感情 / «- Здравствуйте, я пришел снять деньги. - Только не снимайте деньги с меня, иначе я огорчусь. Лучше пойдите к банкомату, у него нет чувств».

Использование дискурсивных формул позволяет приводить в действие процесс интимизации, который очень свойственен современному китайскому банковскому дискурсу. Таким образом, работник китайского банка становится не просто безликим адресантом какой-либо информации, но и личностью, мнение которого становится важным и авторитетным для адресанта, в связи с чем происходит сближение между агентом и клиентом. В целом прецедентные тексты и дискурсивные формулы безусловно играют свою важную роль в речевом поведении работников китайской банковской сферы, в них отражаются ценности представителей банковской сферы, их отношение к работе и клиентам.

Компоненты институционального дискурса: участники, хронотоп, цели, ценности, стратегии, прецедентные тексты, дискурсивные формулы -отчётливо проявляются в китайском банковском дискурсе. Несмотря на то, что все эти компоненты присущи каждому институциональному дискурсу, они имеют особенные характеристики конкретно в китайском банковском дискурсе. Особенная система ценностей, сформировавшаяся в китайском обществе, повлияла на организацию банковской социальной среды и речевую деятельность работников. Ценности определяют ключевые правила профессиональной этики, которая формирует коммуникационную деятельность работников китайского банка. Характеристики клиентов и самих работников банковского дискурса, такие как возраст, пол и другие, определяет приветствия и обращения, используемые рабочими банка, что связано с многовековой традицией почитания старших. Обстановка китайского банка, созданная для максимально комфортного пребывания клиента, и время, в рамках которых происходит дискурс, влияют на общую атмосферу и коммуникацию между агентом и клиентом. Стратегия вежливости и кооперации, используемая работниками банка при коммуникации с клиентами, позволяет достичь цели организации, и также определяет способ общения агентов с клиентами, благоприятный для служения на благо социальному институту банка. Прецедентные тексты и дискурсивные формулы делают речь банковских работников в Китае более оживлённой и естественной, отражая свойственную для работников банковской сферы склонность к интимизации отношений с клиентами. 


\section{Литература}

1. Бурмакина Н.Г., Куликова Л.В. Академический дискурс: Институциональность, стиль, жанры. М.:Изд-во ЛЕНАНД, 2019. $200 \mathrm{c}$.

2. Гибатова Г.Ф. Аксиология языка // Вестник ОГУ. № 2, 2011. С. 127-132.

3. Горелов А.А., Горелова Т.А. Эволюция и смысл культуры. М.: Изд-во «Летний сад», 2015. 480 с.

4. Карасик В.И. О типах дискурса // Языковая личность: институциональный и персональный дискурс: Сб. науч. тр. - Волгоград: Изд-во «Перемена», 2000. С. 5-20.

5. Кирьякова А.В. Теория ценностей - методологический базис аксиологии образования // Аксиология и инноватика образования. 2010. №1. С. 2-32.

6. Махортова Т.Ю. Жанровое пространство банковского дискурса // Актуальные проблемы коммуникации и культуры. № 6. (II). Международный сборник научных трудов. Москва-Пятигорск: Издво Пятигорский государственный лингвистический университет, 2007. С. 463-469.

7. Митькина С.А. Традиционная система ценностей в современной китайской культуре // Научные труды Московского гуманитарного университета, 2018. С. 100106.

8. Федорова (Жарова) А.В. Информационно-коммуникативная среда банковского дискурса // Язык и культура. - Новосибирск, 2014. С. 157-161.

9. 叶勇忠. 银行工作人员职业道. URL: https://wenku.baidu.com/view/2b268ef0dbe f5ef7ba0d4a7302768e9950e76e68.htm (дата обращения 11.11.2020). = Е Юнчжун. Профессиональная этика работников банков [Электронный ресурc]. URL: https://wenku. baidu.com/view/2b268ef0dbef5ef7ba0d4a7 302768e9950e76e68.html (дата обращения 11.11.2020).

\section{Irina G. NAGIBINA,}

Ph. D. (in Philology), Assosiate Professor, Department of East Asian Languages, School of Philology and Language Communication, Siberian Federal University (Krasnoyarsk, Russia).

E-mail: irina_nagibina@mail.ru

\section{Dmitry A. SAVKIN,}

Ph. D. (in Political Sciences), Dean of Baikal School of BRICS, Vice-Rector for International Affairs, Irkutsk National Research Technical University (Irkutsk, Russia).

E-mail: d.savkin@istu.edu

\section{Components of Chinese Banking Discourse}

\section{UDC 811.581'42:330.446.23 DOI https://doi.org/10.24866/2542-1611/2021-3/96-107}

institutional communication,

Chinese banking discourse,

participants, chronotope, strategy of cooperation, values,

case texts,

discursive formulas
The article explores the components of Chinese banking discourse and their linguistic implementation in the discourse of Chinese bank managers. The study examines the verbalization of interactive institutional communication, conditioned by the given framework of the status-role relationship "bank-client" and factors, including communication participants, chronotope, concepts and values, goals and strategies. The findings fill the lack of knowledge about Chinese institutional discourse in general, and its type, Chinese banking discourse, in particular. The considered components of the Chinese discourse form a specialized type of communication within the banking sector of the PRC, which is regulated in accordance with the norms of the studied society. 
For citation: Nagibina I. D., Savkin D. A. Components of Chinese banking discourse // Oriental Institute Journal. 2021. № 3. P. 96-107. DOI https://doi.org/10.24866/2542-1611/2021-3/96-107

\section{References}

1. Burmakina N.G., Kulikova L.V. nauchnykh trudov. Moskva-Pyatigorsk: Izd-vo Akademicheskij diskurs: Institutsional'nost', Pyatigorskij gosudarstvennyj lingvisticheskij stil', zhanry. M.:Izd-vo LENAND, 2019. 200 s. universitet, 2007. S. 463-469.

2. Gibatova G.F. Aksiologiya yazyka // 7. Mit'kina S.A. Traditsionnaya sistema Vestnik OGU. № 2, 2011. S. 127-132.

3. Gorelov A.A., Gorelova tsennostej v sovremennoj kitajskoj kul'ture //

T.A. Nauchnye trudy Moskovskogo gumanitarnogo EHvolyutsiya i smysl kul'tury. M.: Izd-vo universiteta, 2018. S. 100-106. «Letnij sad», 2015. 480 s.

8. Fedorova (ZHarova) A.V.

4. Karasik V.I. O tipakh diskursa // Informatsionno-kommunikativnaya sreda YAzykovaya lichnost': institutsional'nyj i personal'nyj diskurs: Sb. nauch. tr. Volgograd: Izd-vo «Peremena», 2000. S. 5-20.

5. Kir'yakova A.V. Teoriya tsennostej - metodologicheskij bazis aksiologii obrazovaniya // Aksiologiya i innovatika obrazovaniya. 2010. №1. S. 2-32.

6. Makhortova T.YU. ZHanrovoe prostranstvo bankovskogo diskursa // Aktual'nye problemy kommunikatsii i kul'tury. № 6. (II). Mezhdunarodnyj sbornik 11.11.2020). bankovskogo diskursa // YAzyk i kul'tura. Novosibirsk, 2014. S. 157-161.

9. 叶勇忠. 银行工作人员职业道. URL: https://wenku.baidu.com/view/2b268ef0dbe f5ef7ba0d4a7302768e9950e76e68.htm (data obrashheniya 11.11.2020). = E YUnchzhun. Professional'naya ehtika rabotnikov bankov [EHlektronnyj resurs]. URL: https://wenku. baidu.com/view/2b268ef0dbef5ef7ba0d4a73 02768e9950e76e68.html (data obrashheniya 